\title{
Iron Lungs in the Service of Polio Cases Overseas in World War II
}

\author{
HV Wyatt \\ $\mathrm{PhD}$, FIBiol \\ Honorary Research Fellow in Public Health Medicine
}

School of Healthcare Studies, University of Leeds, 18 Blenheim Terrace, Leeds LS2 9HD

\section{Introduction}

For anyone conversant with the literature of poliomyelitis up to 1941 , it would have been realistic to conclude that polio was virtually unknown in the tropics and sub-tropics. There were only two reported papers from Madagascar in the 1930s which concerned a handful of cases following injections (1), although there had also been a small outbreak of 17 cases among the American military and their families in the Philippines in 1936. This had been published in a service journal, Military Surgeon, and was considered a curiosity (2). It was therefore somewhat of a surprise when cases of paralysis among New Zealand soldiers in Egypt from November 1940 to July 1941 were diagnosed as poliomyelitis (3), although the military medical authorities refused to believe the diagnosis (2). An outbreak in Gibraltar in 1941 also caused serious problems of diagnosis (see below). Other cases occurred in the summer of 1941 among Australians in Syria and Cyprus (4) and British troops in Egypt and Cyprus (personal communications).

The official war diaries state that there were no cases of polio in Greece or Crete (5); however, one New Zealand sapper, in the 19th Army Troop, had a very bad attack while in Crete and was left with a paralysed leg. He was captured in this condition (personal communication from his widow).

It was soon evident therefore that poliomyelitis could be a serious problem amongst British and Americans serving in the Middle and Far East, and indeed, as more men poured into these theatres, the number of cases rose. There was a high mortality and respirators were in considerable demand for those with respiratory paralysis. Many stories of heroism, fortitude and skill resulted.

\section{Reports from Available Records}

Lord Nuffield and the Morris Cowley Works, Oxford

Lord Nuffield had respirators built at the Morris Cowley Works in Oxford and distributed to hospitals throughout the Empire (Appendix). Letters from Wilfrid Hobbs Esq, the works manager to both Lord Nuffield and Professor RR MacIntosh of Oxford University are preserved at the Wellcome Library (6). The respirators were used for people with polio and also for a variety of other conditions such as those recovering from accidents, snake bites and drowning.

Respirators were sent abroad to many hospitals including the Royappetah Hospital at Madras, the Mitford Hospital at Decca and the Goculdas Hospital at Bombay.
Lord Nuffield was informed by letter of the lives saved in $\overline{\underline{O}}$ India in 1942 and in the 8th Army in 1943.

For example, in 1940, Dr Moos wrote of a small $\underset{\Omega}{\overparen{\Phi}}$ European girl in Bombay with polio, "she had to stay in longer ... to get her splinted we improvised a larger neck $\overrightarrow{ }$ diaphragm - cutting out the wooden front panelling -.? removing it off the sides ... the arms abducted and have a $\overrightarrow{\vec{\omega}}$ little extra room." Mr Hobbs wrote to M'Lord about Dro Moos's comments "not at all surprised to hear that the climate of Bombay has had its affect $[s i c]$ on the rubber parts of the lung, and think you may like to turn over in $\stackrel{\vec{t}}{\rightarrow}$ your mind the possibility of replacement by some other material for use in tropical countries".

Two years later Major Hooper RAMC, in India wrese about a Nuffield Both respirator borrowed from a ci. hospital which saved the life of a British officer "Unfortunately the motor would not work on our liff $\vec{T}$ voltage. It took us nearly five hours to improvise bellows from the inner tube of the spare wheel of our ?ำ cwt lorry." "It may also interest [Lord Nuffield] to knoq that the rubber bellows are not satisfactory in this count where rubber deteriorates so rapidly."

There were also cases of polio among British childr in Malta between 1920 and 1941 (7) and anecdot⿳亠口冋. evidence that there were occasional cases among adults West Africa and India (see below). In June 1942, the wife of a mission doctor in Srinagar, Kashmir was stricken with paralysis of the diaphragm and intercostal muscles. $\cong$ She was kept alive by artificial respiration given by her $\overrightarrow{\overrightarrow{0}}$ husband and relays of hospital workers. There was, $\exists$ however, an iron lung in the State hospital in the town, but the bellows had burst. They were repaired with an? inner tube and the patient was put on her back in a lorry and transferred to the State hospital, her husband continuing artificial respiration as he knelt beside her (8) There is a slightly different account written by her husband at the time and sent to Lord Nuffield (6). "The electric motor failed twice, the pump three times and the? electric power failed several times and friends, servants 3 and boys of the mission school came to help, eveni through great storms and lightning."

In December 1938 the Reverend WM Price sent to request, for an iron lung, for a large hospital in Shillong, Assam, to Lord Nuffield, care of the Radcliffe Infirmary, Oxford. The Radcliffe Infirmary asked the Government to supply the iron lungs (9); unfortunately, the meagre N records do not say why the request was made or when then lung arrived. 
Gibraltar and Force H 1941

There was uncertainty about the incidence of polio in Gibraltar before the Second World War (WW II) although there was a Drinker respirator in the Colonial Hospital which was later transferred to the Military. A possible case occurred in January 1940 in the wife of a soldier (this may have been a retrospective diagnosis) (personal communication from Colonel, later Professor WIC Morris). However an epidemic started on 13 July 1941 when an aircraftsman was admitted to the Colonial Hospital with polio and on 20 August was flown to the United Kingdom (UK) for further treatment. He had been in a Both mechanical respirator for 14 days (10). Another report however suggests the date was February (11). There followed more than 46 cases of 'benign lymphocytic meningitis' (BLM) and 7 cases of polio $(10,11)$. The high incidence of BLM was not discussed in Medical Headquarters until 1942 although a minority medical opinion at that time was that BLM was actually a mild case of polio (Col Morris, see above). In the summary for November (10), the diagnosis of 'polio' was crossed out and left as Lymphocytic meningitis, but Appendix 2 records "There were 23 cases of BLM in November. All cases recovered. It is considered that the epidemic was a meningitic form of poliomyelitis".

On 31 October, AB Tickner of HMS Sikh was transferred to the Colonial Hospital and placed in a Both neck respirator, but sadly died on 8 November. On 4 November, a seaman from HMS Hermione was admitted (10) with respiratory embarrassment. "The ship's medical officer took his Chief ERA [engine room artificer] to the Colonial Hospital to see the solitary Drinker, already in use. The Chief took notes and drawings. This was midday, and by three o'clock next morning they delivered a replica Drinker apparatus to the Military Hospital complete with relays of ratings to work the hand driven pump. This latter was most ingenious. The ship [a cruiser] carried a spotter sea-plane, amphibian in fact [Walrus]. Its wheels had fat little tyres like dough-nuts. They had taken a spare inner tube, slit it round the circumference, attached one rim to one round board, and the other rim to a similar board. A steel bar ran from the middle of the lower board through the centre of the upper board and terminated in a handle. The pump was worked by a rating standing on top and pumping up and down to a steady count. It was most effective" (personal communication from Dr GB Hollings, then Physician at Gibraltar General Hospital (GH) 10). The Ship's log records "Iron Lung Party (6 ratings) to hospital" at 0235 and "Hospital party returned" at 0315 on 5 November (12) and another "Hospital party" at 1225 next day.

The War Diary records that the iron lung made by HMS Hermione was a box of wood with a felt lining and a sorbo collar. The bellows were worked by hand and timed by a stop watch (10) (Figs 1a,b \&c). On 6 November an officer from the aircraft carrier HMS Ark Royal was admitted with polio. The day after, he was placed in a second improvised iron lung made by the crew of his sh (10). On the 14 November, a Bragg pulsator arrived by air. The records are confusing, but there may have beeक्ष twelve cases of BLM and 4 cases of polio paralysis from seven ships of Force $\mathrm{H}$.

The Colonel, Deputy Director of the Medical Serviceg wrote a letter of appreciation to HMS Hermione saying "I think their achievement is little short of miraculous. Thọ actual construction of the apparatus itself is a beautifo piece of workmanship, but the fact that it was made 호 such a short space of time is even more noteworthy" $(10) \frac{\bar{m}}{\text {. }}$

Sister AE Potter QAIMNS in a persong communication remembers that "one officer and fin ratings from ships of Force $\mathrm{H}$ arrived at the hospital late one afternoon, allegedly suffering from excessive fatigue The wards were full, so they were accommodated in ct detached barrack room across the road". The night sist made a call before she started her normal rounds and to Sister Potter that she "did not at all like the look of son of the group", but there were no empty beds where they could be moved for constant observation. The medic \$ officer on duty was called and the group were moved in 8 two small rooms in the hospital normally used for P(g) or transit patients. They were all subsequently diagnese as polio and survived. By chance, they had be를 effectively isolated.

The Hermione iron lung was featured in an illustro magazine of 14 April 1942 and a short account was

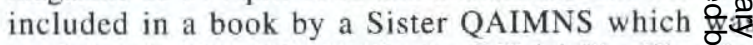
published in 1944 (13). Unlike the Official War Histofiछ of the other Services, the volumes of the Naval Mecosc Service History surprisingly have no sections on polio

Force $\mathrm{H}$ put to sea and on the 13 November HMSç Royal was sunk with HMS Hermione rescuing t survivors (12).

A further case thought to have been a Flight Sergea was placed in the iron lung at the Colonial Hospital on December, but died two days later (10). A further s $\overrightarrow{\vec{a}}$ cases of polio occurred in Gibraltar in 1943 followed one in each of the two subsequent years.

\section{Malta}

Throughout the siege, from 1940 until late 1942, Mal only had one case of polio (14). The children falling si on 15 and 21 November in Malta and Gozo respectiver. were not initially recognised as polio (interviews wi Maltese doctors). The first of many Service cases howevor was diagnosed on 27 November and MB Taylor wrote the Nursing Mirror: "The end of the first fateful we found us with eight patients with severe respirato involvement, and one iron lung. It was soon discoveregl that an unorthodox type of artificial respiration (i.e. rhythmical pressure and release, applied centrally with to palm of the hand on either side of the lower end of the sternum) was of some help ... and an S.O.S. for volunteers to work in fifteen minute relays at this w immediately issued. The response was great. All mad 

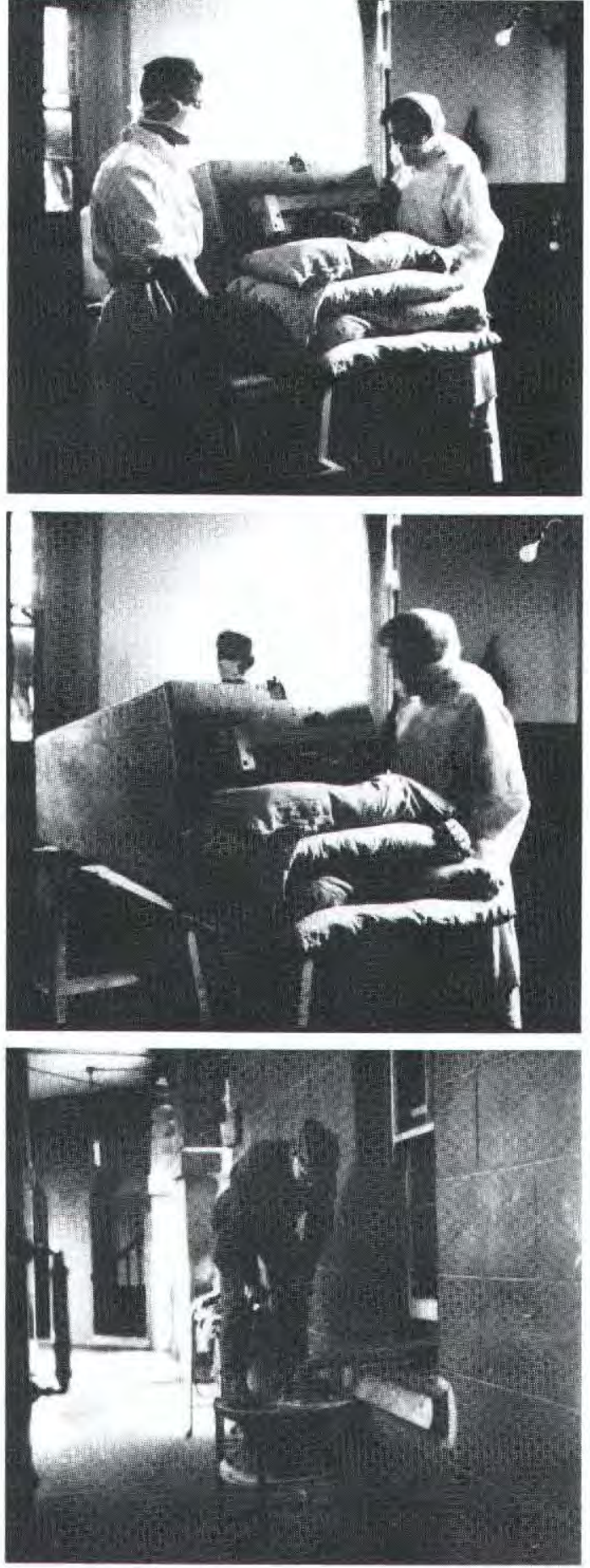

Figs 1a, $1 \mathrm{~b}$ and 1c. The wooden iron lung made by the crew of HMS Hermione at Gibraltar, 1941. The pump was outside the ward and connected with a pressure hose through an open window (11). orderlies not on duty at that time (together with members of the Malta Auxiliary Corps) flocked to the ward, and were soon dressed in gowns and masks, ready for action. When day staff finished duty they, too, hurried along to reinforce the volunteers" (15).

Before the first of three respirators was completed, twoc survivors had shared the one iron lung, taking turns of eight hours each. Miss Taylor continued "Exhaustion caused by the constantly changing over, and by the inadequacy of artificial respiration given when out of the lung, became so marked eventually in Cpl. C., that it was $\frac{\bar{\Phi}}{\bar{\sigma}}$ feared that another move might prove disastrous. Pte $H ., \stackrel{\mathbb{\Omega}}{\varrho}$ (the other survivor), becoming aware of this, offered to forego his turn. An urgent message was then despatched $\rightarrow$ to the appropriate quarter, and an emergency cabinet? arrived, "in the rough", within a few hours. Without $\vec{\omega}$ having been tested in the workshop, this respirator had yet to prove its worth. The spare bellows were attached, and it may be imagined with what awe we watched our? hero's revival within a few minutes of his being placed in $\frac{\vec{A}}{\vec{A}}$ the cabinet".

An officer seriously ill with diphtheria was placed in one respirator while $\mathrm{Cpl}$. C., the weaker of the tig $\frac{\dot{2}}{N}$ polios, was given artificial respiration. Unfortunately t officer died, followed several months later by the two polio cases (post-mortem and case notes held by author $\bar{\delta}-\vec{T}$

"Colonel Tanner, RE had one made using a lar coffin-like box and an ancient forge bellows. I rememb ํํㄹ the date on them was 1909! I don't think it was used. TR discussion between senior medical officers and Tanner [including Ms Bates] was about wheth8re something could be devised using a Mae We (inflatable life jacket used by the RAF) (personồl communication). Lt Col Tanner, RE constructed thret respirators of the Drinker type, incorporating severalo minor modifications which made for greater efficiency (16). He added mirrors and compartments to keep $\stackrel{\mathbb{Q}}{2}$ necessities handy (personal communication, Mrs $\mathrm{HJ} \overrightarrow{\overrightarrow{0}}$ Taylor, then Sister i/c No. 4 Ward, 90 GH, Mtarfa (Figs 3 $2 \mathrm{a}, \mathrm{b} \&$ \& $)$.

Mrs Taylor reported that Col Tanner came to visit one? of his men and found the Sister of the ward almost in tears as she explained the lack of respirators.

The civil Government lent three Nuffield pattern irons lungs to the Army and several Bragg-Paul respirators $\vec{\oplus}$ were sent to the island on instructions from the War Office (17). The two Bragg-Paul respirators were? requested from the Middle East on 1 January 1943 (17) 3 . and arrived in Malta on 6 January 1943 (18). Miss Bates recalled that two iron lungs, one from Egypt and one 3 from Gibraltar were brought by submarine.

In July 1943, Lt Col RE Tunbridge, RAMC wrote a 옹 report on the respiratory difficulties of the patients, stating that by 14 July 1943 there were 61 Service cases, 18 had respiratory paresis, 12 of whom died, 4 were permanent invalids and 2 still required respiratory $N$ assistance after 6 months. He commented that the Bragg-N 

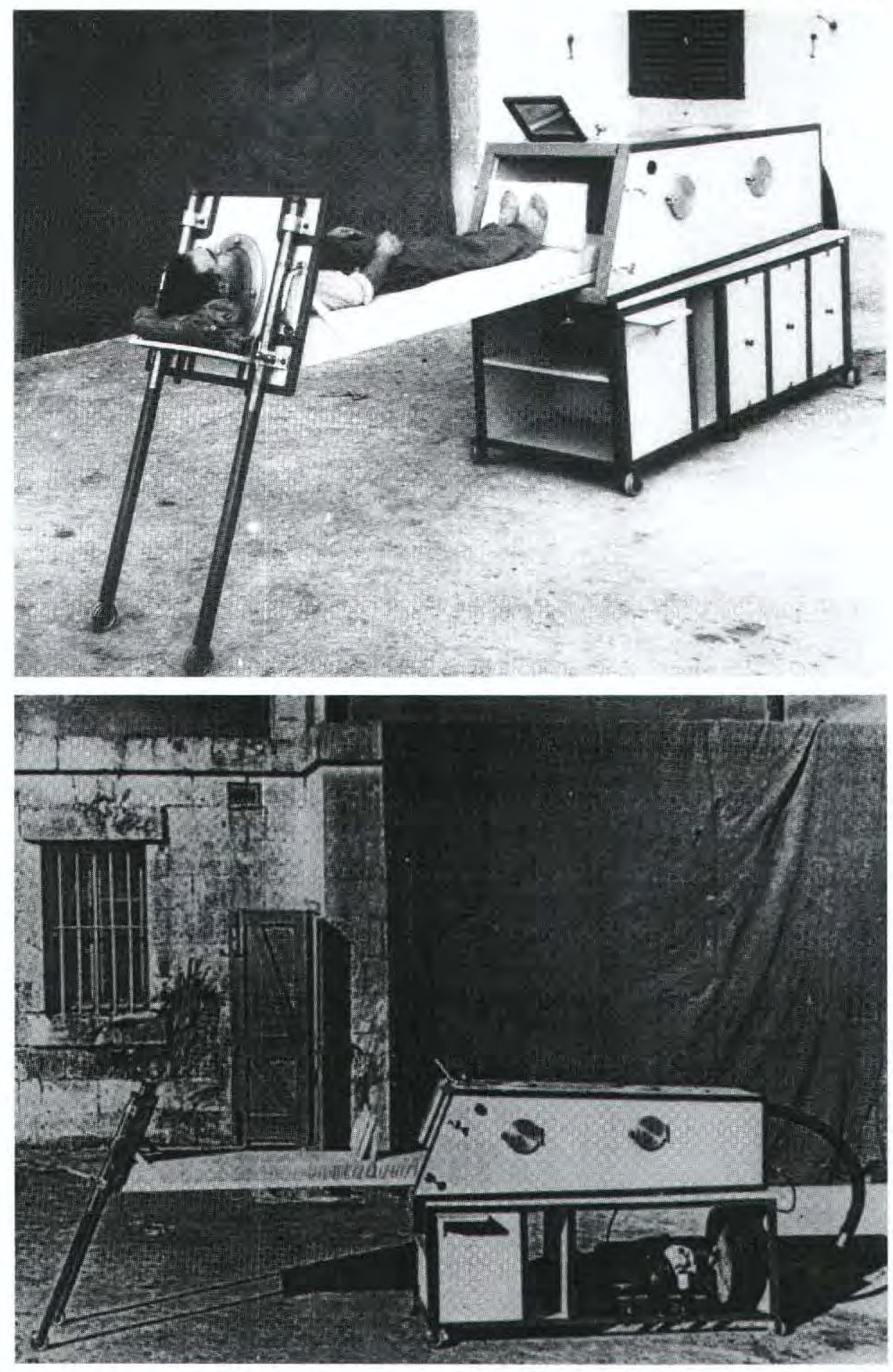

Fig 2a and 2b. The Malta iron lung open and showing the adjustable foot support, mirror and handy shelves. The box with its two opening ports on each side appears to rest on the lower part which housed the engine and bellows (19). 


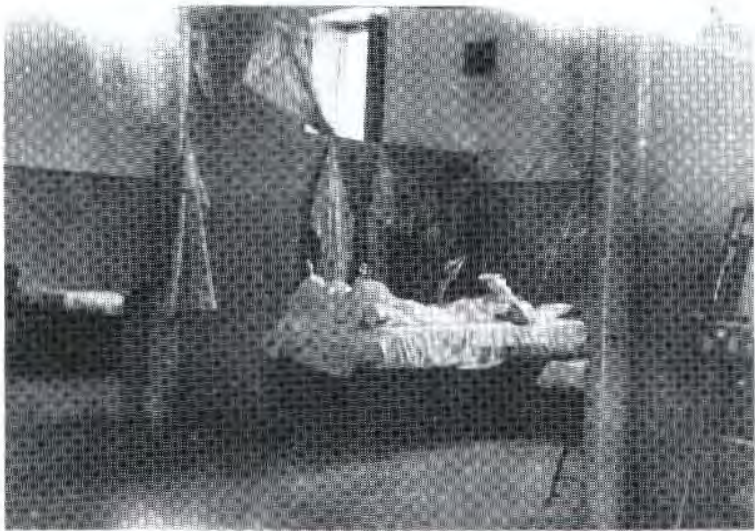

Fig 3. The Polio Ward at 90 General Hospital, Mtarfa, Malta G. C. on 14th January 1943 showing a polio serviceman lying on a bed for a spell out of his Malta iron lung, the end of which is visible on the right. This picture was taken by an RAMC orderly, Mr JR Jones, who sadly passed on before publication of this article.

Paul respirator was small, compact, easy of transport and could be used with the patient on an ordinary stretcher. However, the patients preferred manual assistance as although the Bragg compressed the chest wall, the patient had to assist in inspiration. The Drinker on the other hand was most successful and even patients moribund in the Bragg, revived in the Drinker and were able to sleep. "The Bragg-Paul was useless in Malta - patients disliked it intensely. It cannot be said to have served any useful humanitarian purpose or to have acted as a placebo for professional conscience" (19). The file contains 5 photographs of the Malta iron lung (Figs $2 \mathrm{a} \& \mathrm{~b}$ ).

Noel Coward visited Malta and the hospital in August 1943: "The hospital was impressive and obviously well run. There were some horrors of course. One poor man with some sort of rheumatic paralysis had been in an iron lung for 8 months. He was wonderfully cheerful and he had a photograph of his wife stuck on the ceiling so that he could smile up at her quite easily" (20).

Miss GM Bates in a personal communication commented "Colonel Tanner later had a small swimming bath for hydrotherapy made, just large enough for one man to do exercises in. The water was warmed in some way, I forget how, but it was at a difficult time when there was little fuel in the island."

There was apparently at least one Drinker respirator available for the children with bulbar polio in Saint Luke's Hospital, "but it was difficult to adapt the apparatus to these young patients, and where this was done the benefit was only temporary" (21).

\section{The Middle East, Italy and the Azores}

The records for the Middle East are sparser than for other theatres. In December 1943, 4 RAF Hospital MEF, then at Benghazi in Cyrenaica, noted the arrival of at iron lung. At Foggia in Southern Italy, on 16 November 1944 it was recorded "NCO at present in the Iron Lung'? (22).

"Beginning on June 14 [1944], there followed a sharo and alarming outbreak of acute anterior polymyelitis" ag the RAF Station on the Azores.

There were 5 cases in the first three days, four o whom died of respiratory paralysis within 36-48 hours of the onset of symptoms. In the total of 9 cases occurring irf the first four days, 3 developed serious paralyti symptoms, in addition to the 4 who had fatal respirator paralysis. In the absence of any 'iron lung' an effort waฐ్ made to save the life of the first case by arranging immediately after diagnosis, for his transfer by air to the UK in an operational aircraft accompanied by a MedicaL Officer (MO) and 2 Nursing Orderlies (NOs). Althoug|w the patient received continuous oxygen treatment e店 route, the effort proved unavailing and he died one hous before arrival in the UK (23).

On 17 June 'Pip' Travell flew 2 or possibly 3 cases in $\overrightarrow{\vec{E}}$ Fortress aircraft from the Azores to RAF Lyneham iro Wiltshire, carrying also the MO and 3 orderlies. returned to the Azores on the evening of $19 \mathrm{~J} / \overline{\mathrm{W}} \overrightarrow{\mathrm{N}}$ "urgently with the first iron lung and also the Principas Medical Officer (PMO) of Coastal Command, Air Vㄹe Marshall AE Panter" (personal communication from 융 WR Travell). Unfortunately I have been unable to trạ the PMOs report on the epidemic. "By 20 June, 2 Cabi®e respirators and 1 Bragg-Paul respirator had arrived" (g) The first case had been a Sergeant rigger of 220 Squadgis and it was his companions, a Flight-Sergeant, a Lea通g Aircraftsman (LAC) and a fitter who repaired the b융요 plate of the iron lung which had fractured in trapis (personal communication Mr JP Jackson). Details of th cases are given in other files (24).

India

Between 1932 and 1940 there were 21 recorded case $\$$ of polio, usually severe and fatal, amongst the military of the Punjab and North-West Frontier Province (25). Untiक 1939 , cases had been given manual respiration by relay of orderlies, but in that year an iron lung was improvise in a matter of a few hours. In 1940, a large full automatic machine was built locally, based on the्ट recollection of a Drinker machine seen in England by one Doctor as no diagrams, pictures or drawings wer available. While work was in progress, a periodical wit? pictures of the lung arrived, but there were no details of machinery, measurements or construction. The picture of the local respirator show a sophisticated machine When a Nuffield lung arrived from England, smaller? portable machines were built and distributed to outlyin stations: the pictures show a relatively simple wooder. box. Other respirators may then have been buils elsewhere in India.

The cases among British soldiers rose from 72 in 194h 
52 in 1943,104 in 1944 to 167 in the first 10 months of 1945 (26). There were also cases among Indian troops. At first there were probably only 24 iron lungs, and arrangements were made with the Royal Air Force to fly them within 24 hrs to where they were needed (personal communication, Lt Col JG Fife, IMS Retd).

In the middle of 1944, the Consultant Neurologist, Brigadier D McAlpine submitted a report on polio in India. He had previously been in the Middle East and had flown to Malta in January 1943 to report on the polio epidemic. He reported that "on account of the great distances separating hospitals in India and the possibility of an epidemic it had been considered necessary to make provision for a larger number of iron lungs than the present sporadic incidence of the disease would seem to warrant." Forty one were available, of which 20 were loaned by civil hospitals, and an order for a further 15 was authorised (27). A year later, there were $17 \mathrm{AC}$ and 33 DC electric iron lungs of which 29 were on loan from civil hospitals and return was contemplated. There were also 2 of the Bragg-Paul type as well as 11 hand operated small wooden improvisations. It was felt that 6 more electric instruments were required: "the instruments made by Rawalpindi Arsenal are perfectly satisfactory" (26). By 1944, the Rawalpindi Arsenal had made 27 iron lungs of which 6 had been sent to Ceylon at ALFSEA (28).

"Immediate transfer of an iron lung, often over long distances, is usually requested for [bulbar polio] . . . only to arrive too late. In addition the hasty transit over rough ground, country roads, aerodromes etc., frequently damages the instrument (in one case beyond repair)." The dispersed and more easily portable Bragg-Paul respirators were to be flown to distant stations as required. The Bragg-Paul respirator was an inflatable waistcoat worked by an electric pulsator. It could be sent more easily to outlying places in response to an urgent call. Twelve had been ordered from the UK in late 1944 (through the India Office), but only 6 had arrived, 4 of which had been sent to Ceylon. The various type of iron lung however had been distributed to large hospitals to cover the whole of India. "If transportation of a case in an iron lung by air is needed the 'home made' wooden machine is satisfactory for the purpose. It is worked by orderlies en route" (29).

Except for the small epidemics which were concentrated at Officer Cadet Training Units (OCTU), most cases occurred at random so that hospitals only rarely saw cases. Number 9 RAF GH of SEAAF at Calcutta had only one polio case between January and March 1945 and 5 cases from April to June (22). Of these, one was transferred to a respirator, one returned to duty and three were repatriated to the UK: there were two other deaths due to polio. One polio case, transferred from the Command Military Hospital (CMH) at Entally, was critically ill by the following morning. "An attempt was made to borrow a respirator from the Army Authorities and from the 142nd American Hospital but one could not be spared". From July to September 1945 there was one death due to polio on transfer to CMH Entally. "Oxygen and artificial respiration were given in the ambulance died soon after half the journey [bumpy road]. A Bragt Paul respirator and a Both [from the Army] respirator aक्ल now available".

"Corporal E had been serving with a REME [Royd Electrical and Mechanical Engineers] unit some milos away and had developed a high fever with breathing difficulties which was diagnosed as [poliomyelitis]. HW friends in the unit fabricated a breathing machine with attachment round the chest connected to a hand pump. They sent a signal to our hospital [CMH Dibrugarh, (क) the Brahmaputra, north of the Naga Hills] asking us $\mathbb{Q}$ ) prepare a respirator. After a frenzied search an anciedt and battered 'iron lung' was found mouldering away in? storeroom. When the REME officers and men arrived $\mathbb{P}$ 25 June [1945], having taken turns to pump the homemade respirator throughout the journey, tho checked our machine, only to discover something wro with the circuit. The engineers overhauled the respirat: ready for the next operation, which was a crucial one They had to stop pumping the first machine, slid Corporal $\mathrm{E}$ into the 'iron lung', close the lid and adjust tte sponge-rubber flange round his neck to form a seal, bøore switching on the breathing apparatus. All this theso. dNil admirably with the help of the nursing staff and apparatus took over the corporal's breathing almos th once. It was an exceedingly stressful situation fo요 짐 concerned, particularly for the patient, who completely conscious and well aware that his life w\& stake" (29). Unfortunately, although two REME of stood by in case the respirator needed attention, Corm $\overrightarrow{8}$ E died the next day.

Dibrugarh was not one of the hospitals listed as hami a military respirator (26), so it was probably the iron sent to Shillong in 1938 (see above) which was used f: Corporal E.

A Gunner G, who fell ill in June 1943, was more luck He was taken to $38 \mathrm{BGH}$ at Deolali where Colon Bainbridge "performed a wartime miracle" by arrangio for a ration-truck from another unit to drive nonstop with two drivers to Bombay, more than a hundred miles aw to pick up a Lord Nuffield Drinker iron lung. It could on be operated on Direct Current, which was not available the district so the Royal Signals ran a cable the 10 miless from Nasik City. The patient wrote:"meanwhile I receiv manual assistance from my section of gunners $w \mathbb{Q}$ worked my pump by hand, taking it in shifts for ma hours. They camped in the hospital compound and rallieis around when needed - the cable was many times sever by bullock cart wheels leaving me gasping like a figh when the hospital staff kept me going by artificiz respiration until my team of gunners got organised의 many times passed out from lack of breath until resc arrived - not a bundle of laughs." The iron lung was ma of plywood with an ill-fitting sponge rubber collar whinb leaked. Gunner G survived and is now 80 (personal communication). This iron lung was probably the o used by Dr Moos (6). 


\section{Conclusions}

Poliomyelitis was a very serious medical problem in World War II and many of the cases had respiratory involvement requiring iron lungs. Servicemen built models quickly and efficiently, but the difficulties of isolated cases and terrible road conditions were never really solved. Polio did not go away with peace and respirators were still needed in these out of the way places. For example: in 1955 , the nine year old daughter of a soldier in Benghazi developed respiratory polio. Fortunately there was a REME workshop nearby which made an iron lung out of a coffin. "That was a bit frightening for a little girl, and I fought against the respirator for a while, but eventually it was okay. Then I hated being taken out of it. Also they had to put this black rubber collar around my neck as a seal and that pulled my hair - I didn't like that" (32).

Sister Taylor wrote about "the remarkable degree of mental development following almost complete physical decline [in the two patients in iron lungs in Malta]. It was noticed and remarked upon by both Colonels who visited them on several occasions and found conversation with them of increasing depth and interest" (30). Polio patients may have needed iron lungs, but they provided their own iron wills to survive.

\section{Acknowledgements}

I am very grateful to all those doctors, nurses, servicemen and polios who responded to my requests for information and to the Peel Medical Research Trust and the Wellcome Trust for grants for expenses. Figures 1 and 2 are reproduced by kind permission of the Director of the Public Record Office and Figure 3 by the late Mr JR Jones.

\section{Appendix}

In bulbar, intercostal and diaphragmatic paralysis, the muscles of respiration no longer function and breathing has to be assisted. In 1929 Dr Philip Drinker devised a mechanical respirator, the 'iron lung' with alternate negative and positive pressure to inflate and deflate the lungs(31). There were many US, Australian and European designs of different complexities. The Both respirator, provided by Lord Nuffield, was a wooden box, square in section which could be tilted, and had a pump which could be operated by hand if the electricity failed. It was much simpler than the metal American models. In several of the accounts in this paper, respirators called Drinker may have been the simpler Both type. A smaller 'Cuirass' type fitted over the chest like a breast and back armour was useful for transport and home use.

The Bragg-Paul machine was an inflatable pneumatic jacket which compressed the chest, expiring the air. When the motor operated bellows relaxed the pressure, elastic recoil of the rib cage allowed fresh air into the lungs. In all the respirators, the cycles of compression etc were simple and could be adjusted to coincide with the limited breathing pattern of the patient. Strictly speaking, all should be called respirators rather than iron lungs, but the popular term hog stuck.

Mimi Rudulph was an American musician struck with paralysis, who gave birth to a second child while in an irêfn lung and with exercises and iron will after 22 months left for home. She rebuilt a useful life from wheelchair a d breathing machine, as teacher and producer and on the Councils of UNICEF, World Affairs and the Metropolitain Opera (32). Tony Gould is another who has shown iron waidi (30).

\section{REFERENCES}

1. Wyatt HV. Provocation poliomyelitis: neglect\&d clinical observations from 1914 to 1950. Bull Hist Med 1981; 55: 543-557.

2. PAUL JR. A history of poliomyelitis. Yale University Press, 1971.

3. Caughey Je, Porteous WM. An epidemic $B f$ poliomyelitis occuring among troops in the Mides East. Med J Aust 1946; 1: 5-10. Personal communication from JE Caughey.

4. WALKER AS. Australia in the War of 1939-1949. Medical Services Vol 2. Middle East and Far East. Canberra: Australian War Memorial, 1953.

5. Public Record Office, Kew, England. WO 222/163\% 을

6. Wellcome History of Medicine Library, Lonton, PP/RRM B80.

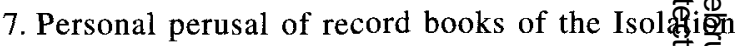
Hospital 1920-1964, medical and physiothega records, interviews and personal communications.

8. Holland H. Frontier Doctor. Hodder, 1958: 207-2A8 $8 \overrightarrow{0}$

9. India Office Library, London. Economic \& Oveuseas Dept 1938. File \#8246.

10. Public Record Office WO 177/1076.

11. Public Record Office WO 177/2190.

12. Public record Office ADM 53/114422.

13. HARRISON A, ED. Grey \& scarlet. Letters from the vis areas by Army sisters on active service. Londor: Hodder \& Stoughton, 1944: 138.

14. Seddon HJ, Agius T, Bernstein HGC, Tunbridge Re. The poliomyelitis epidemic in Malta 1942-43. Quar. Med Sci 1945; 14: 1-26.

15. TAYLOR K. Faith and fortitude in Malta. Incident in nurse's life. Nursing Mirror 25 June 1949. A personal communications.

16. Bernstein HGC, Clark JMP, Tunbridge RE. Ace anterior poliomyelitis among Service personnel Malta. An account of an epidemic. $B r$ Med J 1945; 763-767.

17. Wellcome History of Medicine Library RAMC 2048/20.

18. Public Record Office WO $177 / 1360$.

19. Public Record Office WO 222/151.

20. Coward N. Middle East Diary. London: Heinema 1944: 36. He identified the hospital as Melheia ${ }^{\mathrm{T}} \mathrm{a}$ mistake for Mtarfa. 
21. Debono JE. Poliomyelitis in Malta. Br Med J 1945; 2; 61-62.

22. Public Record Office AIR $29 / 767$.

23. REXFord-Welch. The Royal Air Force Medical Services. Vol 11 Commands. History of the Second World War. London: HMSO, 1955: 320-327.

24. Public Record Office AIR 27/435 and AIR 27/1367.

25. LIPSCOMB FM, HARVEY AC. Breathing machine service in the Northern Command, India. J R Army Med Corps 1942; 79: 57-68. [There are 5 photographs of the machines].

26. BRown D. Report on poliomyelitis in 1945. India Command 1945. Cyclostyled document in possession of author.

27. MCALPINE D. Report on neurology. India Command 1945. Cyclostyled document in possession of author.
28. RAINA BL. Official history of the Indian Armed Forces in the Second World War 1939-45. Medical Services Medicine, surgery and pathology. Combined Inter services historical section, India and Pakistan 195 Delhi.

29. Bolton A. The maturing sun. An Army nurse in Indi@ 1942-1945. London: Imperial War Museum 1986.

30. Gould T. A summer plague. Polio and its survivors London: Yale University Press, 1995: [Tony Gould w a National Service officer with 7th Gurkha Riffes whem he contracted polio in Hong Kong: he was placed in iron lung].

31. MARKEL H. The genesis of the iron lung. Arch Pedia帛 Adolesc Med 1994; 148: 1174-1180.

32. RudulPH M. Inside the iron lung. UK: The Kensal Press, 1984. 